\title{
Determination of Rheological Properties of Fresh Concrete and Similar Materials in a Vibration Rheometer
}

\author{
Sandra Juradin \\ Faculty of Civil Engineering and Architecture University of Split, \\ Matice hrvatske 15, 21000 Split, Croatia
}

Received: July 20, 2011; Revised: October 12, 2011

\begin{abstract}
A vibration rheometer has been developed for the purpose of determining the viscosity coefficient and the yield value of fresh concrete under vibration. The main parts of the apparatus, a test specimen and a vibration source form a unitary oscillatory system whose parameters can be measured with sufficient precision. Two types of fine grained reference material have been prepared and examined; one with a high coefficient of viscosity and the other with a high yield value. The rheological properties of reference materials have been determined in a capillary tube viscometer. Since there is no analytical solution to the flow in the vibration rheometer, the constants of the vibration rheometer have been determined by experiment, for each position of the apparatus piston within the measuring range. The parameters of the flow depend on the maximum acceleration of the vibration source. An increase in acceleration causes an increase in the yield value as well as a reduction in the plastic viscosity coefficient of the material specimen. A testing of fresh mortar has been carried out as well. The obtained results have been compared with the impact on reference materials, which makes the results of our research applicable to fresh vibrated concrete.
\end{abstract}

Keywords: fresh concrete, rheological properties, Bingham model

\section{Introduction}

"Fresh concrete can be viewed as a concentrated suspension of solid particles (aggregates) in a viscous medium, i.e. cement paste" (Neophytou et al., 2010, p. 62402-1) ${ }^{1}$. The behaviour of a specimen of fresh composite material is defined in terms of its workability and is measured by numerous consistency methods. Many researchers have shown that the behaviour of fresh concrete in such conditions can be presented by the Bingham rheological model. Some research ${ }^{2-15}$ studies have been carried out using viscometers that have been modified for the purpose of testing fresh concrete.

Tattersall ${ }^{16,17}$ conducted tests in a mixer-like apparatus. In such an apparatus the yield value g, and the coefficient of plastic viscosity $h$ of fresh concrete specimen were determined. On the basis of the experimental data $\mathrm{N}$ and $\mathrm{T}$, Tattersall also determined the yield stress $\tau_{0}$ and the coefficient of plastic viscosity $\mu$ of fresh concrete as a material. The investigation showed that in such conditions the test specimen:

$T=g+h N$

and concrete as a material

$\tau=\tau_{0}+\mu \dot{\gamma}$

behave like the Bingham model.

The rheology of fresh concrete is mainly related to concrete in static state, whereas the rheology of concrete under vibration is still the subject of numerous researches.

*e-mail: Sandra.Juradin@gradst.hr
Fresh concrete that is not under vibration begins to flow only when the yield stress value is exceeded ${ }^{18-22}$. Many authors have concluded that, when vibration is applied, the yield stress is reduced to the extent that concrete can flow due to its own weight. L'Hermite and Tournom ${ }^{23,24}$ concluded that the angle of internal friction of concrete is reduced during vibration. Dynamic forces were not taken into account.

Krstulović $^{25}$ tested the behaviour of vibrated fresh concrete in the original vibration rheometer and established a solution for the flow of the Bingham rheological model under vibration. An analytical solution was established for the Bingham model affected by external force, the buoyancy of the concrete specimen and the harmonic base excitation.

The vibration rheometer consists of a VB-vessel and a piston that penetrates into the specimen and remoulds it (Figure 1a).

The piston consists of a pencil, weights and an oscillograph. When the piston penetrates into concrete under vibration, the velocity of piston penetration and the amplitude of the mass oscillation are measured. These are the input data for the computer programme that calculates the parameters of the rheological model of the specimen: the yield value and the coefficient of plastic viscosity.

Krstulović defined the dynamic forces acting on concrete exposed to vibration and concluded that the dynamic forces were considerably higher than the static ones for selected oscillation parameters of the vibrating table. Therefore, the flow of concrete is not the result of a change in internal friction, i.e. the yield stress of the material, but of the dynamic forces in the system which overcomes it. 


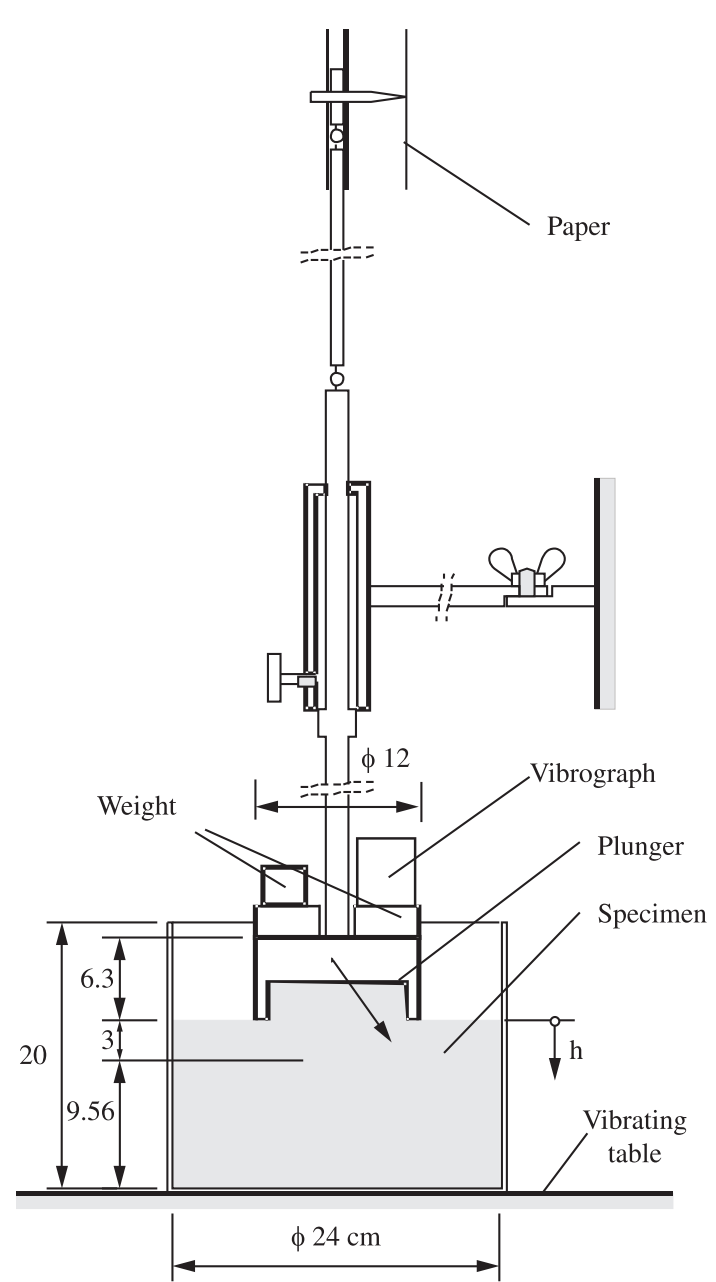

(a)

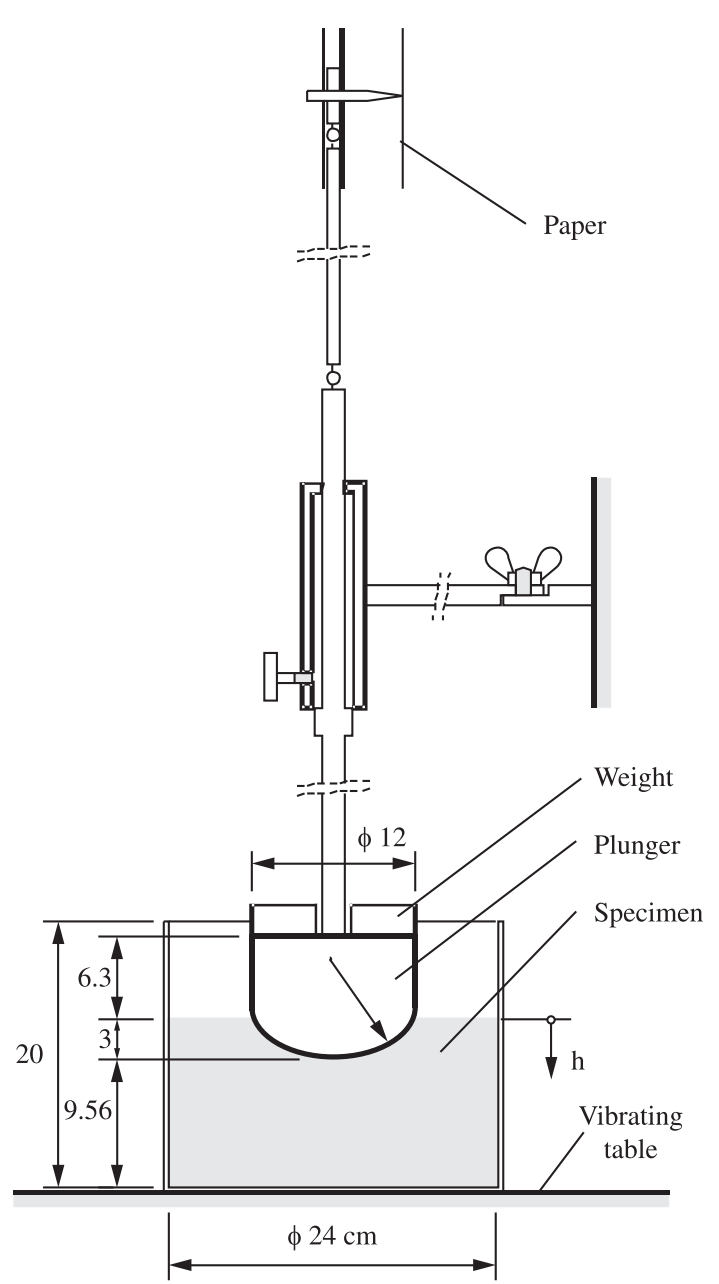

(b)

Figure 1. Vibration rheometer.

Krstulović and Juradin ${ }^{26}$ altered the shape of the vibration rheometer piston (Figure 1b). They tested cement paste and concrete in the apparatus. The input data for the computer programme that calculates the parameters of the rheological model of the specimen are the velocities of piston penetration into the specimen for different piston weights. Using numerical method, the yield value, the coefficient of plastic viscosity and the values of dynamic forces in the system have been determined. The result of the research is shown in the diagram in Figure 2.

The drawing shows the well-known diagram of the Bingham model deformation under the force F. In the existing literature, the force $\mathrm{F}$ is basically static. In this research, the specimen behaves like the Bingham model under vibration, i.e. under combined static and dynamic external forces.

A vibration rheometer can determine the viscosity coefficient and the yield stress of the whole specimen by experiment, but not the viscosity coefficient and the yield stress of the material itself. As there is no theoretical solution for the material flow in a vibration rheometer, the problem should be solved experimentally-theoretically.

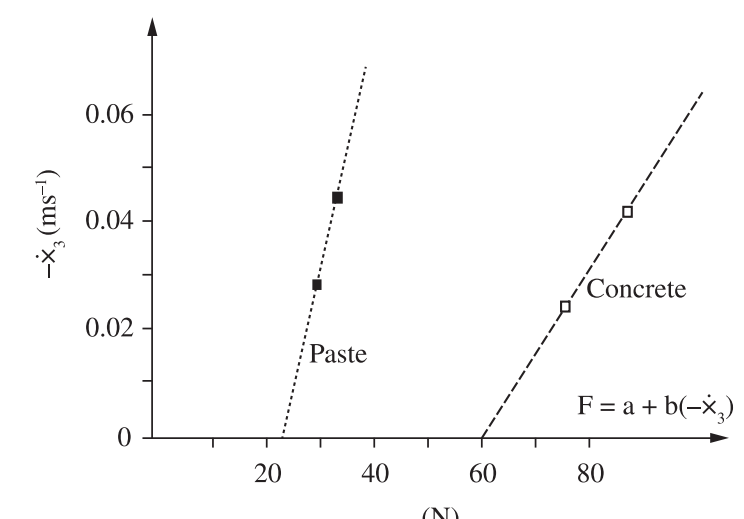

(N)

Figure 2. Diagram of modified Bingham model deformation under vibration for paste and fresh concrete.

Such a method has already been applied by Tattersall ${ }^{16}$ for the purpose of determining the constants of the mixer-like apparatus, without vibration. However, as the results of this and other authors who have tested concrete exposed 
to vibration in the apparatus of the same type are mainly empirical, it is necessary to modify the mentioned principles through the application of the oscillating solution for the Bingham rheological model.

The known general equation of motion for a rotating body in a Newtonian fluid will be applied to a vibration rheometer. The constants should be determined by experiment. Once the constants for every position of the piston of the vibrating rheometer have been determined, the behaviour of the Bingham material specimen in the vibration rheometer can be examined, particularly the variability of the coefficient of plastic viscosity and the yield value, depending on the oscillation amplitude of the vibrating table. The obtained theoretical and experimental results can make a valuable contribution to the theory and mechanisms of concrete vibration.

\section{Apparatus-vibration Rheometer}

The vibration rheometer is shown in Figure 1b. For the purpose of this investigation all parts of the vibration rheometer were left unchanged except that the vessel and the plunger were made smaller.

The vessel in which the specimen is placed is $13 \mathrm{~cm}$ in diameter and $10 \mathrm{~cm}$ high, Figure 3 . The piston is a cylindrical mass, $6.5 \mathrm{~cm}$ in diameter, with the lower end calotte-shaped. The rough-surfaced calotte gradually establishes contact with the specimen. The piston mass can be adjusted by adding different weights and combining them. The weights are screwed to the top of the piston to form a single mass. The mechanical plotter follows the movement of the piston and records the deformation of the specimen.

Once the test material is placed in the vessel, it is necessary to turn on the vibration table for a few moments to have the surface roughly levelled. Then, the piston of the rheometer is returned to its initial position and the vibration table is turned on again. The piston is released to sink freely into the specimen, activating the mechanical plotter. The experiment is finished when the piston has sunk to the final depth, Figure 3.

\section{Rheological Model of Oscillation System and General Analytical Solution}

The behaviour of material oscillation system can be presented with the rheological model subjected to forced vibrations as shown in Figure 4.

According to D'Alambert principle, the differential equation of the dynamic equilibrium is:

$-m \ddot{x}_{1}+m_{2} \ddot{x}_{2}-b \dot{x}_{1}+b \dot{x}_{2}-m g+m_{2} g-a=0$

Where $\mathrm{m}$ is the mass of a material point of the oscillation system, or piston mass:

- $\mathrm{m}_{2}$-the material mass which produces buoyancy to the plunger,

- a-yield value of the specimen. This parameter has a changeable value and sign, dependent on the reciprocal motion of the plunger mass $m$ and a vibrating base,

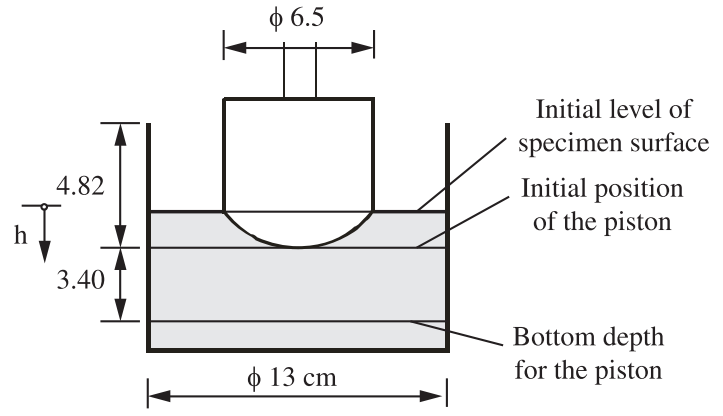

Figure 3. Test specimen.

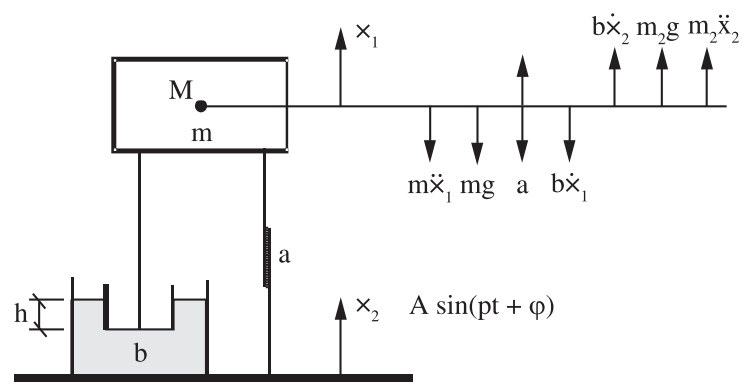

Figure 4. Rheological model of the oscillation system.

- b-coefficient of plastic viscosity of the specimen,

- g-gravitation constant.

General solution to the differential Equation 3 can be written as:

$x_{1}=C_{1}+C_{2} e^{-\frac{b}{m} t}-\frac{m_{1} g+a}{b} t+A_{1}^{\prime} \sin (p t-\varepsilon)$

where:

- $\mathrm{C}_{1}, \mathrm{C}_{2}$-integration constants,

- $\mathrm{t}$ - time,

- $p$-angular frequency, $p=2 \pi f$, (f-frequency),

- $\mathrm{m}_{1}=\mathrm{m}-\mathrm{m}_{2}$,

- $A_{1}^{\prime}=\frac{\sqrt{\left(m m_{2} p^{2}+b^{2}\right)^{2}+\left(m_{1} p b\right)^{2}}}{m^{2} p^{2}+b^{2}} A$ - partial amplitude to which the mass $m$ would oscillate in the case of a particular solution, $\mathrm{p}$ is the angular frequency of a forced oscillation of the material point $M$, and $\varepsilon$ is partial phase angle relevant to the oscillation of the sub-base.

Expressions for the values of integration constants are derived for a steady state of the oscillatory system. That is the state when the oscillation of the material point $\mathrm{M}$ becomes periodic, with the same frequency as the oscillation source.

The system can oscillate in several ways, depending on the values of the parameters $\mathrm{A}, \mathrm{p}, \mathrm{m}, \mathrm{m}_{1}$, a and $\mathrm{b}$. For each particular group of parameters, different expressions for the values of integration constants are obtained for the steady state. Six different types of oscillation can appear. 


\subsection{Determination of the yield value $a$ and the coefficient of plastic viscosity $b$ of the material specimen}

As a result of the experiment, a piston penetration versus time record is obtained and shown in Figure 5.

In order to establish the connection between the yield value a and the coefficient of plastic viscosity $b$, the velocities of piston penetration at all depths can be determined as a slope of the tangents ${ }^{25,26}$ :

$$
\mathrm{K}=\operatorname{tg} \alpha
$$

For one oscillation period the piston sinking depth $\mathrm{h}$ is considered $\mathrm{h}=$ const. Therefore, the difference between two end points of one oscillation period is parallel to the tangent of recording, hence the Equation 6:

$$
\frac{x_{15}-x_{11}}{2 \pi}=\frac{K}{p}
$$

where $x_{11}$ is the first and $x_{15}$ is the second point of one oscillation period, which differs for the period of $2 \pi$, Figure 6.

The mentioned equation can be written as follows:

$$
x_{15}-x_{11}-2 \pi \frac{K_{1}}{p}=0
$$

and represents the first equation for determining the parameters $a$ and $b$.

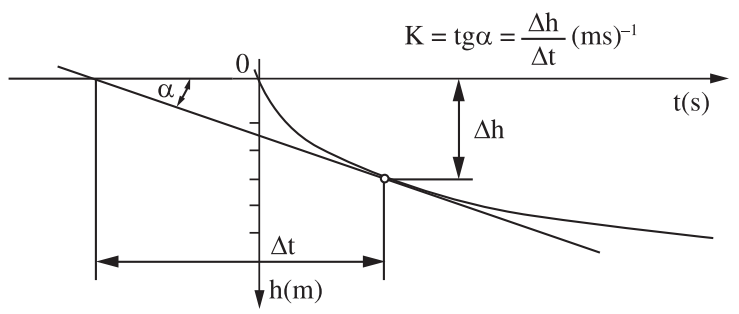

Figure 5. Piston penetration vs. time record and determination of the principle of penetration velocity.

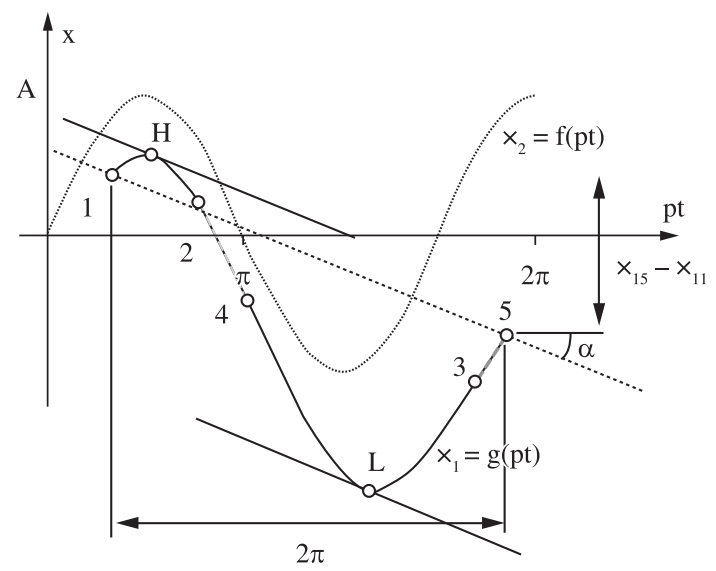

Figure 6. The vertical displacement of material point $\mathrm{M}$ in one oscillation period.
The second equation of the same form is obtained by determining a new slope of the tangent- $\mathrm{K}_{2}$ in a test with a different load $\mathrm{m}$. The expressions $\mathrm{x}_{11}$ and $\mathrm{x}_{15}$ are derived from the Equation 4.

The solution to the obtained non linear equations, given in implicit form, can be sought only numerically. The input data for the programme are $\pi, g, \mathrm{p}, \mathrm{A}, \rho, \mathrm{h}$, and the data pair $\mathrm{K}_{\mathrm{i}}$ and $\mathrm{m}_{\mathrm{i}}$ obtained by experiment. The computer programme has been developed by applying the tangent method, which is also known as Newton's method. If the experiment is made with more than two loads $m$ or if individual tests are repeated, then more than two values for $\mathrm{K}$ are available. It is much better to define the parameters a and $b$ based on more than two pairs of data $\left(\mathrm{K}_{\mathrm{i}}\right.$, $\mathrm{m}_{\mathrm{i}}$ ), implementing the correlation method from the theory of mathematical statistics.

The basic equation is a general expression for the least sum of aberration squares:

$\mathrm{S}^{2}=\frac{1}{\mathrm{~N}} \sum_{\mathrm{i}}\left(K_{\mathrm{i}}-k_{\mathrm{i}}\right)^{2}=\min$

where $\mathrm{K}_{\mathrm{i}}$ are measured and $\mathrm{k}_{\mathrm{i}}$ are theoretical values of penetration velocities.

The problem is nonlinear and can be solved only numerically. The value of the correlation index, as a measure of correlation quality, is obtained ${ }^{26}$ :

$$
R_{x y}^{2}=\frac{\frac{1}{N} \sum_{i} k_{i}^{2}-\bar{k}^{2}}{\frac{1}{N} \sum_{i} K_{i}^{2}-\bar{k}^{2}}
$$

\subsection{Determination of the yield stress $\tau_{0}$ and the coefficient of viscosity $\mu$}

It is not possible to develop a theoretical flow solution for a vibration rheometer. The problem is even more complicated due to the fact that the piston is only partially immersed into the sample. Therefore, the solution can be obtained only by experiment. Tattersall ${ }^{16,17}$ tested a series of pseudoplastic fluids with known rheological properties using a mixer and determined the apparatus coefficients. In order to apply this principle to the vibration rheometer, a specific reference material must be tested in it, which would behave as the Bingham model, or pseudoplastic fluid, parameters of which can be determined in a capillary tube or a rotational viscometer. Penetration of the piston into a Newtonian fluid specimen is defined by the general equation of rotary body motion in a fluid ${ }^{4}$ :

$$
F=N D \pi K \eta
$$

where the coefficient $\mathrm{N}$ depends on the shape of the rotary body and the vessel containing the fluid.

The differential Equation 3 can also be written as:

$F=a+b\left(\dot{x}_{1}-\dot{x}_{2}\right)$

or

$F=a+b K$ 
The starting assumption here is that the material and the specimen in the apparatus behave according to the same model. For the fluid flow, the following equation is valid:

$\dot{\gamma}=G K$

where $\mathrm{G}$ is the apparatus constant.

The behaviour of Bingham material can also be defined by the apparent viscosity equation ${ }^{16,4}$ :

$$
\eta^{\prime}=\frac{\tau_{0}}{\dot{\gamma}}+\mu
$$

Combination of expressions for $\eta^{\prime},(10),(11)$ and (12) finally gives:

$$
N=\frac{b}{D \pi \mu}, G=\frac{N D \pi \tau_{0}}{a}=\frac{b}{a} \frac{\tau_{0}}{\mu}
$$

To determine the values $\mathrm{N}$ and $\mathrm{G}$ for the vibration rheometer, at least one reference material should be at disposal. In order to justify the Equation 12, verification on at least one more reference material with different characteristics is required.

\section{Test Specimen-reference Materials}

For the purpose of determining the vibration rheometer constants, the reference material specimen needs to be tested both in the apparatus and in the viscometer with the known analytical flow solution. Cement concrete is not suitable for such purpose, because a sample of fresh concrete undergoes chemical changes immediately after it comes into contact with water. Bleeding of water is inevitable in fresh concrete and testing under vibration additionally mixes the sample, so the results differ from the test without vibration. There is also the constraint of the maximum aggregate grain size, during the testing in the viscometer.

For the same reason, Westerholm et al. ${ }^{27}$ developed an artificial paste as a substitute for cement paste, for the purpose of testing the influence of crushed fine aggregate on rheological properties of mortar. The artificial paste consisted of a blend of dispersed silica fume, fine quartz and water.

For the purposes of this research, the reference material, i.e. a mixture of solid particles and fluid that must behave as the Bingham model, must comply with the following conditions:

- the sample must be stable, free of bleeding of fluid phase and segregation;

- the sample may not change the spatial model with the elapsed time, particularly during the experiment;

- the material properties must enable testing in both types of apparatus within normal measuring range.

If the first two conditions are fulfilled, the experiment can be repeated on the same sample an unlimited number of times. The liquid phase must have a significantly higher viscosity coefficient than water, and low evaporation, the condition almost fully met by mineral oils, produced in a vast viscosity range. The maximum grain is, for practical reasons, limited to $0.25 \mathrm{~mm}$. The testing required fractions of fine grained, i.e. powder material, to allow for varying mixture compostiton. Three different fractions with $0-0.125 \mathrm{~mm}$ and a $0.125-0.25 \mathrm{~mm}$ fraction were obtained from $\mathrm{CaCO}_{3}$ and silica fume $\left(\mathrm{SiO}_{2}\right)$ was at disposal as a special fraction. After a series of test mixtures, two were selected as reference. The spatial model of both mixtures is presented in Figure 7. The first mixture consists of motor oil SAE $15 \mathrm{~W}-40$, with the viscosity coefficient $\eta=0.258$ Pas, and the other mixture consists of mineral oil-INSTRUMENTOL, which does not contain anticoagulant, with $\eta=0.039$ Pas.

The unit weight of mixture $\mathrm{A}$ is $\rho \mathrm{A}=1.894 \mathrm{~g} . \mathrm{cm}^{-3}$ and of mixture $B$ is $\rho B=1.874$ g.cm ${ }^{-3}$.

\section{Experimental Results and Discussion}

\subsection{Testing in the capillary tube viscometer}

The theoretical flow solutions exist for coaxial-cylinders and capillary tube viscometer. They are usually used for the purpose of determining the coefficient of viscosity $\mu$ and the yield value $\tau_{0}$ of a material behaving as the Bingham model. For the test purposes, a capillary tube viscometer was selected and constructed because, for a Bingham material, it has the same range of velocity gradient as a vibration rheometer.

Theoretically, a corresponding flow can be calculated for every pressure, based on the Equation 15:

$Q=\frac{\pi R^{4} \Delta p}{8 l \mu}\left[1-\frac{4}{3}\left(\frac{2 l}{R \Delta p}\right) \tau_{0}+\frac{1}{3}\left(\frac{2 l}{R \Delta p}\right)^{4} \tau_{0}{ }^{4}\right]$

If, for two pressure values $\Delta \mathrm{p}$, the corresponding pressures $q$ are measured, the solution of a two equation system gives the parameters $\mu$ and $\tau_{0}$. A better solution is obtained with a larger number of data pairs $(\Delta p, q)$. The basic equation is a general expression for the least sum of aberration squares:

$$
S^{2}=\frac{1}{N} \sum_{i}\left(q_{i}-Q_{i}\right)^{2}=\min
$$

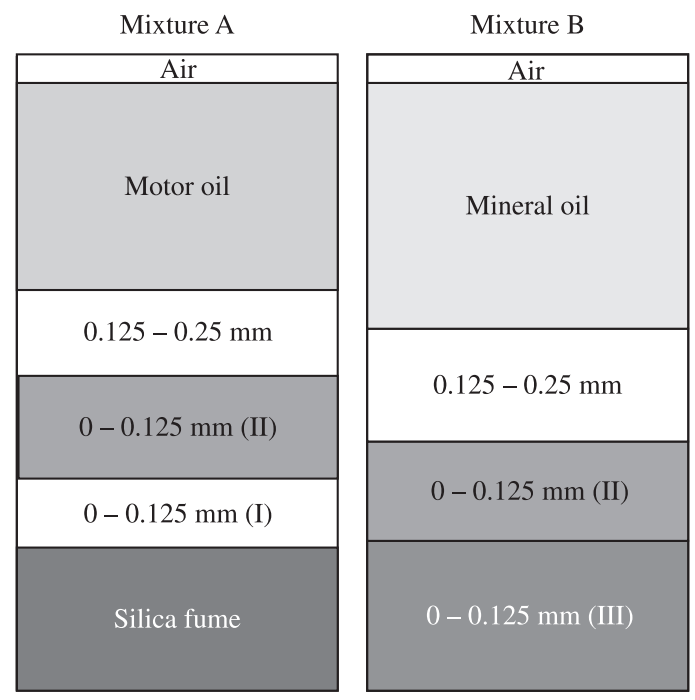

Figure 7. Spatial models of specimens for Mixture A and B. 
where $\mathrm{q}_{\mathrm{i}}$ are the measured and $\mathrm{Q}_{\mathrm{i}}$ are the calculated flows, based on the Equation 15. For that purpose, a computer programme has been developed that computates the values of the required parameters to the set accuracy. Simultaneously, the value of the correlation index as a measure of correlation quality is obtained:

$$
R_{x y}^{2}=\frac{\frac{1}{N} \sum_{i} Q_{i}^{2}-\bar{q}^{2}}{\frac{1}{N} \sum_{i} q_{i}^{2}-\bar{q}^{2}}
$$

By means of computer data processing, the following values of the coefficient of viscosity and the yield stress were obtained for:

- mixture $\mathrm{A}: \mu_{\mathrm{A}}=62.3 \mathrm{Pas}, \tau_{0 \mathrm{~A}}=66.6 \mathrm{~Pa}, \mathrm{R}_{\mathrm{xy}}=0.9993$,

- mixture $\mathrm{B}: \mu_{\mathrm{B}}=13.46 \mathrm{Pas}, \tau_{0 \mathrm{~B}}=433.7 \mathrm{~Pa}, \mathrm{R}_{\mathrm{xy}}=0.8692$.

It can be observed that the viscosity coefficient is dominant in mixture $\mathrm{A}$ and the yield stress in mixture B. It is known that in a mixture of solid particles and fluid, solid particles obstruct the flow, so that these mixtures have a higher coefficient of viscosity than the fluid alone. The Westerholm et al. ${ }^{27}$ found that " $[. .$.$] the large amounts of fines$ primarily increase the yield stress of the mortar. The amount of fines also contributes to the plastic viscosity increased by interparticle friction" (2008, p. 274)

High yield stress in mixture B the is the result of intermolecular forces between particles. This is confirmed by the fact that the volume concentration of particles in mixture $B$ is significantly smaller than in mixture $A$, and the fact that mixture $\mathrm{B}$ does not contain filter $\mathrm{SiO}_{2}$ powder, which gives the major contribution to the yield stress in mixture $\mathrm{A}$.

When using experimental mixtures, it has been observed that distinct yield stress can only be obtained by adding a high volume concentration of colloidal particles to the specimen. It is a well-known fact in the rheology of pigmented varnishes and putties.

The first variant of mixture A selected for testing in the capillary tube viscometer failed because the yield stress was very small and weakly expressed. Thus, a new mixture was created with a significantly increased amount of $\mathrm{SiO}_{2}$ powder. However, it must not be forgotten that, apart from the fact that the viscosity coefficient of the oil in mixture A exceeds the one in mixture B by 6.6 times, it contains more additives, including, among others, an additive that prevents coagulation.

This is confirmed by the following experiment. If, in an extracted sample of mixture B, only $1 \%$ of oil containing an anticoagulant (e.g. HIDRAOL HD-20 or motor oil SAE 5W-40) is added to the mass of oil already contained in the mixture, the yield stress disappears completely and the sample spills onto the base, thus behaving as pseudoplastic fluid $^{22}$.

\subsection{Testing in the vibration rheometer}

A sample volume in the rheometer vessel must be the same for all tests. The rheometer vessel is fixed to the vibrating table; the piston is inserted into the guides and is set in starting position. The guide is connected to a mechanical printer. In the test under vibration, the vibrating table is activated first, followed by the printer and the screw on the piston guide is released.

The tests were performed with four different piston loads $\mathrm{m}=561,684,801$ and $924 \mathrm{~g}$. The first test series started with the lowest mass and finished with the largest one, whereas the second series started with the largest mass and finished with the lowest one. The velocity of piston penetration into the sample is described graphically, by constructing the tangent of the recording curve. The measuring field of piston penetration into the sample is $3.4 \mathrm{~cm}$ (Figure 3). Greater depth is not convenient due to the proximity of container bottom. The measuring field is divided into five points, in the direction of which the coefficient of the recording tangent is determined, i.e. the velocity of piston penetration (Figure 5).

- Testing under vibration; Mixture A was tested with three different amplitude values $2 \mathrm{~A}=0.15,0.30$ and $0.50 \mathrm{~mm}$, and mixture $\mathrm{B}$ with amplitudes $2 \mathrm{~A}=0.20$, 0.35 and $0.50 \mathrm{~mm}$.

In each point, four figures for piston penetration velocity, $\mathrm{k}$, were obtained for each direction of load change, which was 8 figures in total. The data was processed by a developed computer programme and the yield value of the specimen, a, as well as the coefficient of plastic viscosity of the specimen, $b$, were obtained for all five depths.

- Testing without vibration; The main assumption was that the samples would behave as the Bingham model, which is described by the Equation 11a.

In this case, $\mathrm{F}$ is the force reduced by the value of buoyancy, due to piston mass, i.e. $F=m_{1} g$. Based on the eight available figures, the parameters a and b could be calculated for each mentioned depth, using the linear correlation method.

The results obtained for mixture A are presented in Table 1.

Mixture B constituted a problem. Due to relatively high yield stress, the test without vibration required much larger masses. Only 2 pairs of data, a and b, were determined (Table 2).

- Vibration rheometer constants. The apparatus constants $\mathrm{N}$ and $\mathrm{G}$ are derived from the results of the tests performed in the capillary tube viscometer and vibration rheometer. They are obtained under equal conditions, i.e. without vibration. By inserting the rheometer dimensions, the Equation 14 becomes:

$N=\frac{b}{D \pi \mu}=\frac{b}{0.065 \pi \mu}, G=\frac{b}{a} \frac{\tau_{0}}{\mu}$

As for mixture A, all values of the parameters $a$ and $b$ exist per depths, and the coefficients $\mathrm{N}$ and $\mathrm{G}$ are defined. Two results for mixture B appear to be very similar, so the constants $\mathrm{N}$ and $\mathrm{G}$, obtained for mixture $\mathrm{A}$, are used to calculate the $\mathrm{a}$ and $\mathrm{b}$ parameters for mixture $\mathrm{B}$ at all depths (Table 3).

Krstulović ${ }^{25}$ tested a glycerine sample in an apparatus that had the same dimensions but different piston bottom shape. For the depth $\mathrm{h}=0.030 \mathrm{~m}$, he obtained $\mathrm{N}=29.14$. Using Table 1, for the mentioned depth, $\mathrm{N}=30.35$ was obtained by means of linear interpolation, which presents almost the identical value. This result confirms, one more time, that the vibration rheometer constants $\mathrm{N}$ and $\mathrm{G}$ are generally valid. 
Table 1. Testing without vibration: parameters $a$ and $b$ for mixture $\mathrm{A}$, vibration rheometer constants $\mathrm{N}$ and $\mathrm{G}$.

\begin{tabular}{cccrcc}
\hline $\begin{array}{c}\mathbf{h} \\
(\mathbf{m})\end{array}$ & $\begin{array}{c}\mathbf{a} \\
(\mathbf{N})\end{array}$ & $\begin{array}{c}\mathbf{b} \\
(\mathbf{N s m})\end{array}$ & $\mathbf{N}$ & $\begin{array}{c}\mathbf{G} \\
(\mathbf{m})\end{array}$ & $\begin{array}{c}\mathbf{G} / \mathbf{N} \\
(\mathbf{m})\end{array}$ \\
\hline 0.010 & 2.12 & 121.40 & 9.54 & 61.22 & 6.42 \\
0.016 & 2.21 & 162.88 & 12.81 & 78.80 & 6.15 \\
0.022 & 2.19 & 226.13 & 17.78 & 110.38 & 6.21 \\
0.028 & 2.08 & 328.06 & 25.79 & 168.62 & 6.54 \\
0.034 & 1.90 & 502.10 & 39.47 & 282.50 & 7.16 \\
\hline
\end{tabular}

Table 2. Testing without vibration: parameters a and $\mathrm{b}$ for mixture $\mathrm{B}$, vibration rheometer constants $\mathrm{N}$ and $\mathrm{G}$.

\begin{tabular}{cccccc}
\hline $\begin{array}{c}\mathbf{h} \\
(\mathbf{m})\end{array}$ & $\begin{array}{c}\mathbf{a} \\
(\mathbf{N})\end{array}$ & $\begin{array}{c}\mathbf{b} \\
(\mathbf{N s m})\end{array}$ & $\mathbf{N}$ & $\begin{array}{c}\mathbf{G} \\
(\mathbf{m})\end{array}$ & $\begin{array}{c}\mathbf{G} / \mathbf{N} \\
(\mathbf{m})\end{array}$ \\
\hline 0.016 & 11.73 & 32.9 & 11.97 & 90.37 & 7.55 \\
0.022 & 14.25 & 46.1 & 16.77 & 104.24 & 6.22 \\
\hline
\end{tabular}

Table 3. Calculated parameters a and b for Mixture B, testing without vibration.

\begin{tabular}{|c|c|c|c|}
\hline $\begin{array}{c}\text { h } \\
(\mathbf{m})\end{array}$ & & $\begin{array}{c}a=\frac{N}{G} D \pi \tau_{o} \\
(\mathbf{N})\end{array}$ & $\begin{array}{c}\mathbf{b}=\mathbf{N D} \pi \mu \\
(\mathbf{N s m})\end{array}$ \\
\hline 0.016 & \multirow{4}{*}{$\begin{array}{l}\mu=13.46 \mathrm{Pas} \\
\tau \mathrm{o}=433.7 \mathrm{~Pa}\end{array}$} & 14.40 & 35.2 \\
\hline 0.022 & & 14.26 & 48.9 \\
\hline 0.028 & & 13.54 & 70.9 \\
\hline 0.034 & & 12.37 & 108.5 \\
\hline
\end{tabular}

\subsection{Test results}

\subsubsection{Mixture A}

In the diagrams presenting the dependence of the parameters $\mathrm{a}$ and $\mathrm{b}$ on the oscillation amplitude A (Figure 8), it can be observed that the parameter $b$ decreases to a certain degree, as the amplitude increases, for each depth of piston penetration.

On the other hand, the yield value of the sample increases with the increase of the oscillation amplitude, for all penetration depths. Given that the parameter a practically doesn't change at depth $h$, all the diagrams form a narrow field. This can be explained in the following way: the ideal Bingham material does not exist, but every material is more or less thixotropic ${ }^{28,29}$. Although this characteristic is not pronouncedly expressed in mixture A, the effect of thixotropy is significant. The effect can be shown by the quality diagram in Figure 9.

The behaviour of the material in arbitrary diagram point A (Figure 9) can be shown by the Bingham model, represented by a straight line marked by dot lines. With an increase in strain rate $\dot{\gamma}$, the line becomes more abrupt and vice versa. This causes an increase in the segment on $\mathrm{x}$-axis and yield value $\tau_{\mathrm{A}}$, whereas the cotangent of angle $\beta$, i.e. the coefficient of viscosity decreases. This is entirely in

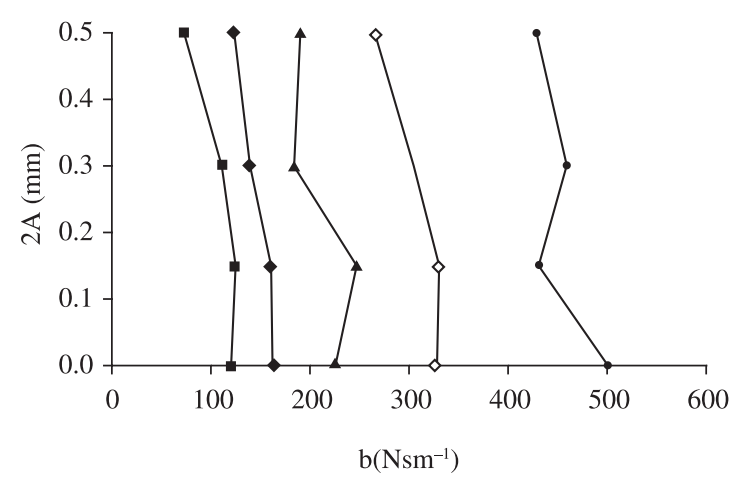

(a)

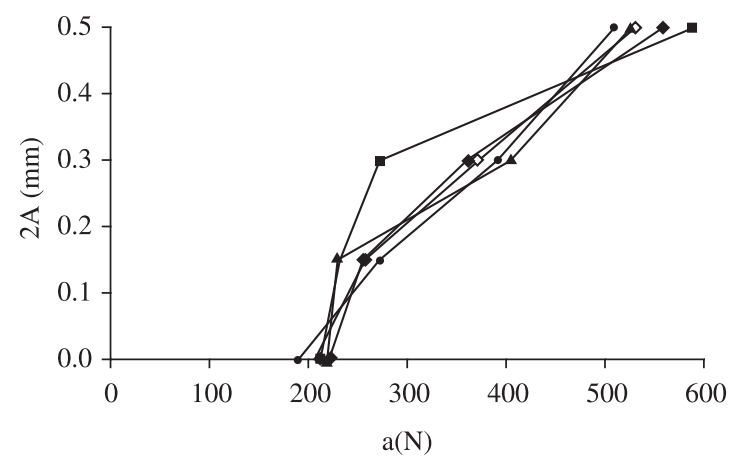

(b)

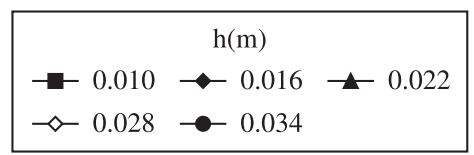

Figure 8. Diagrams b-2A and a-2A for Mixture A.

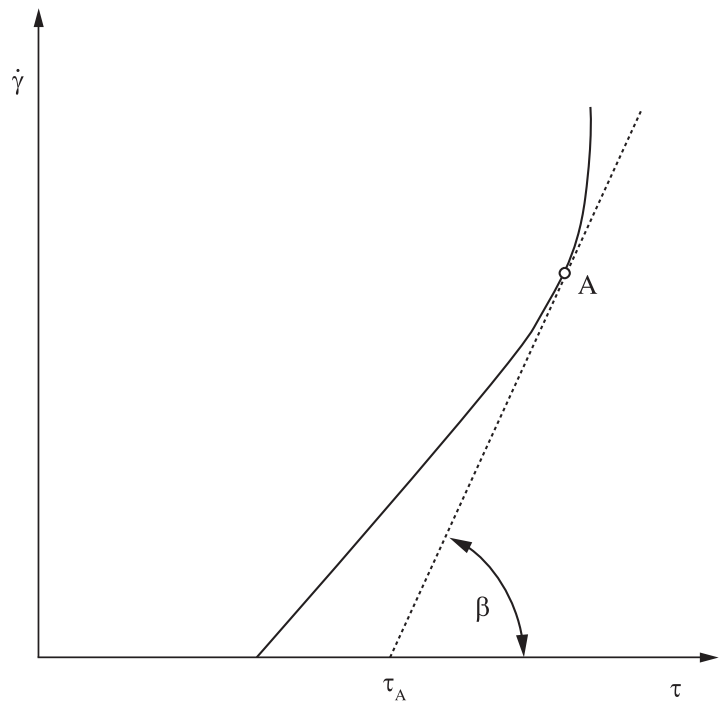

Figure 9. The effect of thixotropic structure on yield value and coefficient of viscosity. 
accordance with the situation shown in Figure 8, where with an increase in the parameter $a$, the parameter $b$ decreases to some degree. With an increase in amplitude, the deformation velocity $\mathrm{K}$ increases, which causes the described changes of the parameters $a$ and $b$.

Desov $^{31}$ came to the same conclusion, testing cement paste and concrete in vibro viscometer.

\subsubsection{Mixture B}

The diagrams for mixture $\mathrm{B}$ show that the yield value of the sample first decreases abruptly due to an increase in the oscillation amplitude, then increases again, Figure 10. It is obvious that by subjecting the sample to vibration, the thixotropic structure is partially broken. The change in structure is maximal during the transition from the state without vibration to the state under vibration. With an increase in amplitude, the change is smaller, but can be observed with each amplitude change.

During the test without vibration, deformation velocities are relatively small, and motion is performed in the existing thixotropic structure. However, by subjecting the specimen to vibration, the structure changes abruptly.

The values of the parameter a and the static force $\mathrm{G}=\mathrm{m}_{1} \mathrm{~g}$ at depth $\mathrm{h}=0.022 \mathrm{~m}$, for both mixtures are presented in Table 4.

For mixture A, the parameter a is smaller than the static force, which makes tests with selected masses without vibration possible.

For mixture $\mathrm{B}$, it is evident that the specimen does not deform under static force, because $\mathrm{m}_{1} \mathrm{~g}<\mathrm{a}$, for all values of $\mathrm{m}$. According to Krstulović ${ }^{25,26}$, the specimen deformation is possible only when the minimum acceleration of vibrating table is exceeded:

$\left(A p^{2}\right)_{\min }=\frac{a}{m_{1}}-g$

As for mixture $\mathrm{B}$, the amplitude must be minimally $0.16 \mathrm{~mm}$ for the applied piston masses, which is confirmed by experiment. The test was performed with the minimum amplitude $2 \mathrm{~A}=0.20 \mathrm{~mm}$. At amplitudes exceeding $2 \mathrm{~A}=0.20 \mathrm{~mm}$ the sample of mixture B behaves similarly as the sample of mixture A. In both samples, at higher oscillation amplitudes, higher deformation velocities, $\mathrm{k}$, occur, a higher yield value of the specimen a and a lower coefficient of the plastic viscosity of the specimen, $b$. However, in condition without vibration, defining the parameters $\mathrm{a}$ and $\mathrm{b}$ in mixture $\mathrm{B}$ is performed at a significantly higher velocity of deformation $\mathrm{K}$ than in any other test with vibration. This leads to the conclusion that the described changes in thixotropic structure depend more on the acceleration of the specimen $\mathrm{Ap}^{2}$ than on the velocity of deformation $\mathrm{K}$.

\subsubsection{Appendix-mortar}

In order to make the above mentioned conclusions applicable to concrete and similar materials, the experiment had to be repeated on fresh concrete. On the other hand, on account of the size of the vibration rheometer apparatus, it was desirable to perform tests with cement mortar. It was decided that a test will be performed with mortar containing the maximum aggregate grain of $\mathrm{D}=4 \mathrm{~mm}$. The recipe for this micro concrete-mortar enabled us to test the test specimen with 4 different piston masses.

The cement used was CEM II/B-S $42.5 \mathrm{~N}$, with the density of 3.09 g.cm ${ }^{-3}$ and the specific Blaine surface area of $3233 \mathrm{~cm}^{2} \cdot \mathrm{g}^{-1}$. The ratios, by mass, of cement, sand and water in mortar were 1.0:1.60:0.36 (C:S:W). The mortar was

Table 4. Values of parameter a and static force $\mathrm{mg}$ for both mixtures at depth $\mathrm{h}=0.022 \mathrm{~m}$.

\begin{tabular}{|c|c|c|c|c|}
\hline \multirow[t]{2}{*}{$\mathbf{m}$} & \multicolumn{2}{|c|}{ Mixture A } & \multicolumn{2}{|c|}{ Mixture B } \\
\hline & mg & $\mathbf{a}$ & mg & $\mathbf{a}$ \\
\hline $0.561 \mathrm{~kg}$ & $3.32 \mathrm{~N}$ & & $3.34 \mathrm{~N}$ & \\
\hline $0.684 \mathrm{~kg}$ & $4.52 \mathrm{~N}$ & 10 & $4.54 \mathrm{~N}$ & \\
\hline $0.801 \mathrm{~kg}$ & $5.67 \mathrm{~N}$ & 2.19 & $5.67 \mathrm{~N}$ & $14.201 \mathrm{~N}$ \\
\hline $0.924 \mathrm{~kg}$ & $6.88 \mathrm{~N}$ & & $6.90 \mathrm{~N}$ & \\
\hline
\end{tabular}
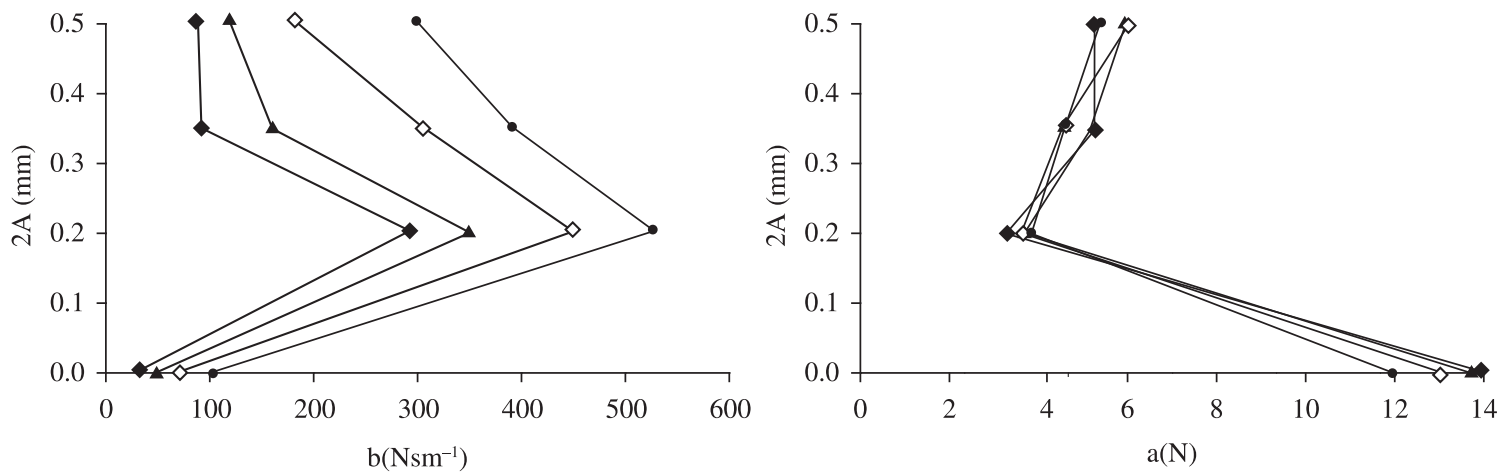

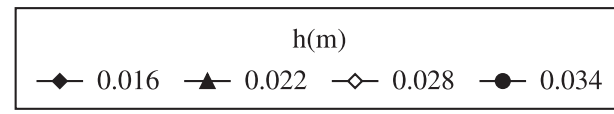

(a)

Figure 10. Diagrams b-2A and a-2A for Mixture B. 
prepared in a mortar mixer by a standard procedure that is applied in cement testing.

As fresh mortar specimens tend to change relatively quickly, a new one had to be prepared for every new test.

The results of the mortar testing in the vibraction rheometer are shown in Figure 11.

The mortar diagram has a shape similar to the one for mixture B, so the same conclusion can be applied to it. In the test without vibration, the same problem occurred

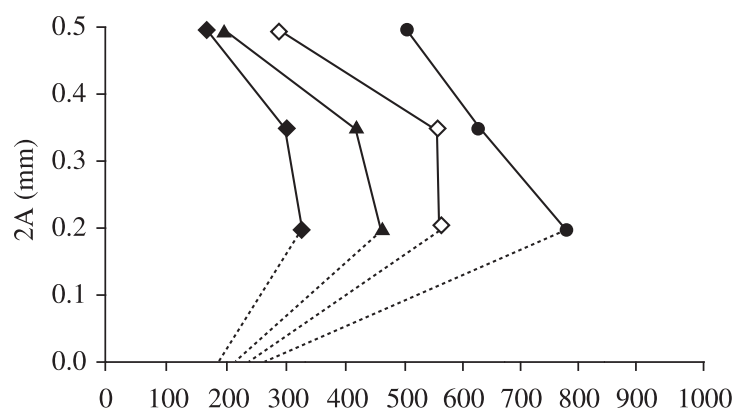

$\mathrm{b}\left(\mathrm{Nsm}^{-1}\right)$

(a)

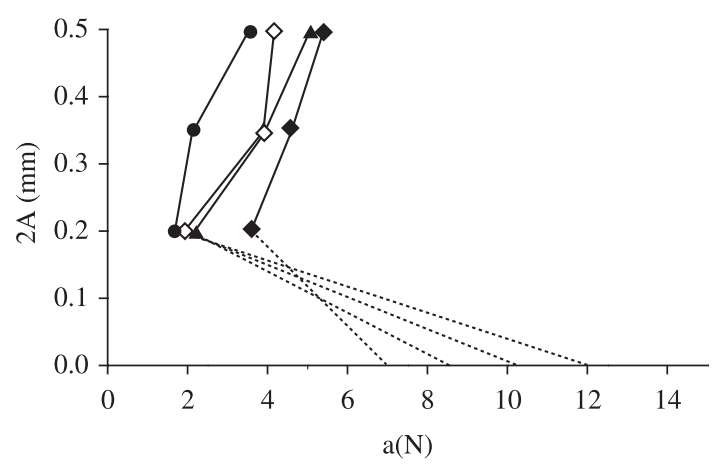

(b)

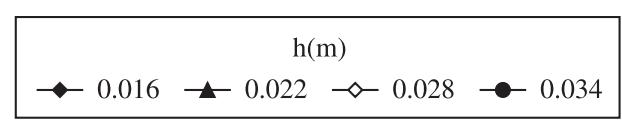

Figure 11. Diagrams b-2A and a-2A for Mortar.

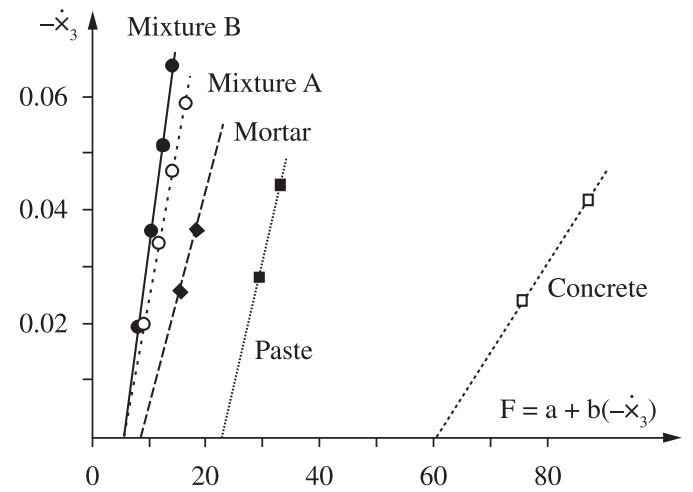

Figure 12. Diagram of modified Bingham model deformation under vibration for mixture $\mathrm{A}$, mixture $\mathrm{B}$ and Mortar. with mortar as with mixture $\mathrm{B}$, due to its relatively high yield value. Therefore, significantly larger masses were used in this case (as in mixture B). Only two data pairs were defined for $a$ and $b$. As mortar cannot be tested in a capillary tube viscometer, due to the maximum aggregate size, the coefficient of viscosity and the yield value cannot be determined, nor can the vibration rheometer constants $\mathrm{N}$ and $\mathrm{G}$ be used to determine the parameters $\mathrm{a}$ and $\mathrm{b}$ at different depths in condition without vibration. These values were determined using an interpolation method and are marked with dotted lines in Figure 11.

After presenting the deformation of mixtures A, B and Mortar in the deformation diagram of the Bingham model exposed to force F (Equation 11a), Figure 12 is obtained.

The obtained diagram for mixtures A, B and Mortar corresponds with the diagram which Krstulović and Juradin ${ }^{26}$ obtained for cement paste and fresh concrete, Figure 2. The obtained values for the force $\mathrm{F}$ are lower due to lower values of masses used and smaller dimensions of the vibration rheometer. Therefore, the following authors' conclusions appear to be applicable to mixtures A, B and Mortar: "[...] the behaviour of the fresh concrete specimen behaves as a Bingham model also under vibration, i.e., under static and dynamic external forces combined. The yield value a and coefficient of plastic viscosity $b$ remain fundamental parameters of the specimen behaviour in a given apparatus, at least for the ranges of penetration velocities as measured in the test" (Krstulović and Juradin, 1999, p. 51) ${ }^{26}$.

\section{Conclusions}

Fresh concrete is a material that changes its mechanical and chemical properties with the lapse of time as well as due to its exposure to testing. For this reason, a new specimen had to be prepared for each test. In order to allow multiple repetitions of the experiment on the same specimen, a reference material was made that was chemically stable and that in such testing conditions did not change its spatial and rheological properties and could be tested in any type of viscometer. This allowed investigation of the effects that are difficult to investigate by means of classical fresh concrete tests. The following conclusions were derived from the tests with such materials.

Combining fluid and solid particles did not result in making an ideal material that would behave exactly like the Bingham model. Any kind of such a composite had a certain degree of thixotropy.

As there is no analytical solution to specimen motion for a vibration rheometer, the apparatus constants were defined by experiment for each position of the piston within the measuring field. The values of the constants were applied to all types of material that behave as the Bingham model. By determining the constants of the apparatus, a connection was established between the viscosity parameter $b$ and the yield stress a of the specimen in the vibration rheometer and the coefficient of viscosity and the yield stress of the material.

The viscosity parameter of the specimen $b$ increases with the depth of piston penetration, and the yield stress of the specimen does not change depending on the depth of piston penetration, or changes slightly. The viscosity parameter $b$ 
and the yield stress of the specimen depend on the rate of specimen deformation. With increasing deformation, the yield stress increases and the viscosity parameter decreases, and vice versa. Therefore, the assumption that the material and the specimen behave like the Bingham model is valid for a sufficiently narrow area of velocity. This parameter change occurs due to changes in thixotropic structure of materials at different velocities.

The change of thixotropic structure of material, and therefore of its rheological properties, depends to a large extent on the acceleration of the specimen, due to vibration effects. For each material there is the minimum acceleration, where a change in thixotropic structure begins.

Testing was performed on two reference materials: mixture A and B. Mixture A is a mixture of motor oil, $\mathrm{SiO}_{2}$

\section{References}

1. Neophytou MK-A, Pourgouri S, Kanellopoulos AD, Petrou MF, Ioannou I, Georgiou G et al. Determination of the rheological parameters of self-compacting concrete matrix using slump flow test. Applied Rheology. 2010; 20:62402-1-62402-20.

2. Murata J and Kikukawa H. Studies on rheological analysis of fresh concrete. In: Proceedings of the RILEM Seminar: Fresh concrete; 1973; Leeds. RILEM Publications SARL; 1973.

3. De Larrard F, Hu C, Sedran T, Szitkar JC, Joly M, Claux F et al. A New Rheometer for Soft-toFluid Fresh Concrete. ACI Materials Journal. 1997; 94(3):234-243.

4. Reiner M. Deformation, Strain and Flow. London: H. K. Lewis \& Co.; 1969.

5. Ferraris CF and De Larrard F. Testing and Modeling of Fresh Concrete Rheology, NISTIR 6094. Gaithersburg: National Institute of Standards and Technology; 1998.

6. Whorlow RW. Rheological Technicques. Chichester: John Willey \& Sons - Ellis Horwood Ltd.; 1980.

7. Hackley AV and Ferraris CF. Guide to Rheological Nomenclature: Measurement in Ceramic Particulare Systems. Gaithersburg: National Institute of Standards and Technology; 2001. NIST Special Publication 946.

8. Ferraris CF, De Larrard F and Martys N. Fresh Concrete Rheology - Recent Developments. In: Proceedings of the VI Materials Science of Concrete; 2001, Westerville. Westerville: American Ceramic Society; 2001.

9. Ferraris CF and Gaidis JM. Connection Between the Rheology of Concrete and Rheology of Cement Paste. ACI Materials Journal. 1992; 89(4):388-393.

10. Cabrera JG and Hopkins CJ. A modification of the Tattersall two - point test apparatus for measuring concrete workability. Magazine of Concrete Research. 1984; 36(129):237-239. http://dx.doi.org/10.1680/macr.1984.36.129.237

11. Pashias $\mathrm{N}$ and Boger DV. A fifty cent rheometer for yield stress measurement. Journal of Rheology. 1996; 40(6):1179-1189. http://dx.doi.org/10.1122/1.550780

12. Alfani R, Grizzuti N, Guerrini GL and Lezzi G. The use of the capillary rheometer for the rheological evaluation of extrudable cement-based materials 28. Rheological Acta. 2007; 46:703-709. http://dx.doi.org/10.1007/s00397-007-0164-0 powder and ground limestone $0-0.25 \mathrm{~mm}$, and mixture $\mathrm{B}$ is a mixture of white mineral oil with a low viscosity coefficient and ground limestone $0-0.25 \mathrm{~mm}$.

By adjusting the size distribution of solid components and the characteristics of the liquid phase, it was achieved that mixture A had a more pronounced viscosity coefficient, and mixture B yield stress. These two characteristics were particularly observable in the testing in the rheometer without vibration. An additional testing was performed with mortar with the maximum grain size $4 \mathrm{~mm}$. Some significant impacts on reference materials were compared with those established for fresh concrete that are described in the literature. For that reason, the results of this research can be applied to all types of concrete, which the results obtained with mortar also show.

13. Chappuis J. Rheological measurements with cement pastes in viscosimeters: a comprehensive approach. In: Banfill PFG, editor. Rheology of fresh cement and concrete. In: Proceedings of the International Conference organized by the British Society of Rheology; 1990; Liverpool. London: E \& FN Spon; 1991. p. 3-12.

14. Struble L, Szecsy R, Lei W-G and Sun G-K. Rheology of cement paste and concrete. Cement, Concrete and Aggregates. 1998; 20(2):269-277. http://dx.doi.org/10.1520/CCA10421J

15. Castro AL and Liborio JBL. Initial Rheological Description of High Performance Concretes. Materials Research. 2006; 9(4):405-410. http://dx.doi.org/10.1590/S151614392006000400011

16. Tattersall GH and Bloomer SJ. Further development of twopoint test for workability and extension of its range. Magazine of Concrete Research. 1979; 31(109):202-210. http://dx.doi. org/10.1680/macr.1979.31.109.202

17. Tattersall GH. Workability and Quality Control of Concrete. London: E. \& F. N. Spon; 1991.

18. American Concrete Institute - ACI Committee 309. Behaviour of Fresh Concrete During Vibration. ACI Journal. 1981; 78(1):36-53.

19. American Concrete Institute - ACI Committee 309. Behaviour of Fresh Concrete During Vibration. reapproved. ACI, 1998.

20. Nazari A and Riahi S. ZrO2 Nanoparticles' Effects on Split Tensile Strength of Self Compacting Concrete. Materials Research. 2010; 13(4):485-495. http://dx.doi.org/10.1590/ S1516-14392010000400011

21. Nazari A and Riahi S. The Effects of $\mathrm{ZrO} 2$ Nanoparticles on Physical and Mechanical Properties of High Strength Self Compacting Concrete. Materials Research. 2010; 13(4):551-556. http://dx.doi.org/10.1590/S 151614392010000400019

22. Nazari A and Riahi S. The Effects of $\mathrm{ZnO} 2$ Nanoparticles on Strength Assessments and Water Permeability of Concrete in Different Curing Media. Materials Research. 2011; 14(2):178-188. http://dx.doi.org/10.1590/S151614392011005000030

23. L'Hermite R. La rheologie du beton frais et la vibration. Institut technique du batiment et des travaux publics. Annales. 1949; (14). 
24. L'Hermite R and Tournon G. La vibration du beton frais. Centre de etude et de recherches de l'industrie des liants hidrauliques. Tehnical publication. 1948; (2).

25. Krstulović P. The rheological characteristics of vibrated fresh concrete. [Tese]. Zagreb: Faculty of Civil Engineering, University of Zagreb; 1991.

26. Krstulović P and Juradin S. Modeling of fresh concrete behaviour under vibration. International Journal for Engineering Modelling. 1999; 12(1-4):43-51.

27. Westerholm M, Lagerblad B, Silfwerbrand J and Forssberg E. Influence of fine aggregate characteristics on the rheological properties of mortars. Cement and Concrete
Composites. 2008; 30(4):274-282. http://dx.doi.org/10.1016/j. cemconcomp.2007.08.008

28. Ružić S. Determination of Rheological Properties of Fresh Vibrated Concrete. [Dissertação]. Zagreb: Faculty of Civil Engineering, University of Zagreb; 1997.

29. Jarny S, Roussel N, Le Roy R and Coussot P. Thixotropic behavior of fresh cement paste from inclined plane flow measurements. Applied Rheology. 2008; 18:14251-1-14251-8.

30. Powers TC. The Properties of Fresh Concrete. Slough: Cement and Concrete Association, Wexham Springs; 1976.

31. Desov AE. Structural Viscosity of Cement and Concrete Mixes. Kolloid Zhur. 1951; 13(5):346-356. 